\title{
Higher prevalence of left ventricular hypertrophy in two Māori cohorts: findings from the Hauora Manawa/Community Heart Study
}

\author{
Gillian A. Whalley, ${ }^{1}$ Suzanne Pitama, ${ }^{2}$ Richard W. Troughton, ${ }^{3}$ Rob N. Doughty, ${ }^{4}$ Greg D. Gamble, ${ }^{4}$ Tawhirimatea Gillies, ${ }^{2}$ \\ J. Elisabeth Wells, ${ }^{5}$ Allamanda Faatoese, ${ }^{3}$ Tania Huria, ${ }^{2}$ Mark Richards, ${ }^{3}$ Vicky A. Cameron ${ }^{3}$
}

\footnotetext{
ardiovascular disease (CVD) is the leading cause of mortality in New Zealand (NZ). Mortality rates are
} higher within the indigenous - or Māori population, ${ }^{1}$ and CVD occurs about a decade earlier in life in Māori compared with the non-Māori population. For example, $45 \%$ of coronary artery heart disease (CAD) deaths in Māori occur before 65 years of age, compared with $11 \%$ for non-Māori. ${ }^{2}$ The relative risk of coronary events between 45 and 64 years is 4.39 (95\% Cl 3.81-5.06) for females, and 3.01 (95\% Cl 2.77-3.28) for males. Similarly, heart failure mortality rates are higher in younger Māori (45-64 years): compared to non-Māori the relative risk of developing heart failure was 4.8 (95\% Cl 1.44-15.93) for females and $10.4(95 \% \mathrm{Cl} 3.52-28.61)$ for males. In older ( $>64$ years) Māori: the relative risk of developing heart failure was $2.3(95 \% \mathrm{Cl} 1.75-$ 3.03) for females and $1.89(95 \% \mathrm{Cl} 1.30-1.76)$ for males. Age and gender standardised stroke incidence is also higher for Māori vs non-Māori. ${ }^{2}$ Like CAD, stroke also occurs at a lower age, with a mean age of 62 years for Māori versus 75 years for non-Māori. ${ }^{3}$

Stroke and CAD share risk factors, including smoking, hypertension and type 2 diabetes mellitus (T2DM), which are also significantly higher in Māori compared to non-Māori, as are obstructive sleep apnoea and proteinuric renal disease $\mathrm{e}^{4,5}$ - also linked to CVD.

Recognised hypertension is more prevalent

\begin{abstract}
Objectives: Cardiovascular disease (CVD) is the leading cause of mortality in New Zealand with a disproportionate burden of disease in the Mãori population. The Hauora Manawa Project investigated the prevalence of cardiovascular risk factors and CVD in randomly selected Mãori and non-Māori participants. This paper reports the prevalence of structural changes in the heart. Methods: A total of 252 rural Māori, 243 urban Māori; and 256 urban non-Māori underwent echocardiography to assess cardiac structure and function. Multivariable logistic regression was used to determine variables associated with heart size.

Results: Left ventricular (LV) mass measurements were largest in the rural Māori cohort (183.5,sd 61.4), intermediate in the urban Māori cohort (169.7,sd 57.1) and smallest in the nonMāori cohort (152.6,sd 46.7; $p<0.001)$. Similar patterns were observed for other measurements and indexation had no impact. One-third (32.3\%) met the gender-based ASE criteria for LV hypertrophy (LVH) with higher prevalence in both Maori cohorts (highest in the rural cohort). There were three significant predictors of LVH: rural Māori $(p=0.0001)$; age $(p<0.0001)$; and gender $(p=0.0048)$.

Conclusion: Structural and functional heart abnormalities are more prevalent in Māori compared to non-Māori, and especially rural Māori. Early identification should lead to better management, ultimately improving life expectancy and quality of life.

Key words: Māori, cardiovascular disease, echocardiography, rural, indigenous
\end{abstract}

in Māori men (43\% versus $27 \%$ in NZEuropean men) and in women ( $31 \%$ versus $18 \%$ ) and perhaps more striking is the rate of undetected hypertension (9\% for Māori men compared with $3 \%$ for NZ-European men, and $5 \%$ for Māori women compared with $1 \%$ for NZ-European women). ${ }^{6}$ Hypertension and T2DM often coexist, and the prevalence of T2DM in Māori is reported at 2.8 times greater than in the NZ-European population.?

\begin{abstract}
Echocardiography provides a non-invasive way to assess the end-organ involvement of cardiac structural and functional changes, such as left ventricular hypertrophy (LVH), associated with hypertension and diabetes. However, echocardiography is typically only available to symptomatic patients and, in NZ, it is usually performed within the hospital system through physician referral. General practice access to echocardiography is limited
\end{abstract}

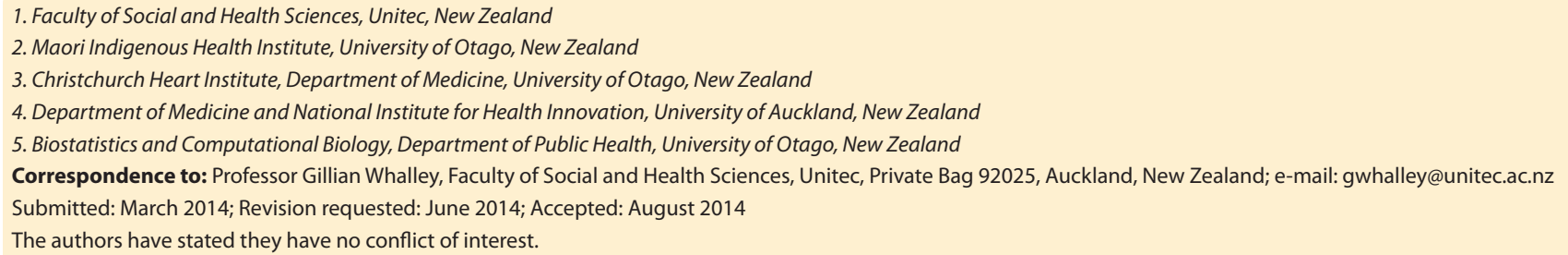


in NZ, and usually only for specific purposes, such as evaluation of heart murmurs.

Historically, it has been difficult to offer echocardiography in smaller centres, in part due to the size and relative immobility of imaging systems, but the advent of laptopsized machines now allows echocardiography to be applied in remote locations. Therefore, if there were proven benefits of wider application of echocardiography to new populations and potentially asymptomatic high-risk populations, this would now be entirely feasible and potentially cost- and lifesaving in the long-term. We have previously reported higher CVD risk in both Māori cohorts of this study compared to the nonMāori cohort, with the highest risk observed in the rural Māori cohort, ${ }^{8}$ and that treatment may be suboptimal. We hypothesise that LVH prevalence may also be higher in the Māori community with a similar difference between the rural and urban cohorts, partly reflective of differing access to healthcare services. Thus, as part of a wider study of cardiovascular risk factors in Māori, the aim of this study was to determine the prevalence of LVH in a remote, rural, predominantly Māori community and compare this with an urban Māori community and an urban non-Māori community.

\section{Methods}

The Hauora Manawa Project, or The Community Heart Study, was established to gather prevalence data for cardiovascular risk factors and established cardiovascular disease within randomly selected samples from two different Māori Communities (Ngati Kahungunu ki Wairoa in rural Hawkes Bay and Ngai Tahu ki Waitaha in urban Christchurch) and a non-Māori urban Christchurch cohort, to identify objective markers to guide monitoring of cardiovascular disease risk (as determined by the NZ cardiovascular guidelines $)^{9}$ and to follow and document the implementation and outcomes of interventions for study participants..$^{10}$ This was a population-based study that used a Kaupapa Māori approach (a conceptual framework that places Māori values, beliefs and experiences at the centre of the research process and locates resultant data within that social context) ${ }^{11}$ with participants randomly selected from the electoral rolls (electoral roll registration is mandatory in NZ). A simple random sample was used without replacement from each stratum, specifying the number to be selected. Full details of sample selection are published elsewhere. ${ }^{10}$ The roll was stratified by age (20-29; 30-39; 40-49; 50-64) and by gender. For both Māori cohorts, everyone in the age range 20-64 years had an equal probability of selection. However, the Christchurch non-Mãori cohort was frequency matched to the age- and gender-group distribution of the Christchurch Māori descent sample. The overall study methods (including selection) have been previously documented. ${ }^{8,10}$ Briefly, all participants who provided informed consent completed a series of health and societal questionnaires, had blood samples taken and had body height and weight measured and body mass index (BMI) calculated. Body composition was assessed by bioimpedance using the Tanita Body Composition Analyzer, TBF 310 (Tanita Inc, Tokyo, Japan). Participants were examined by a cardiologist or physician and underwent cardiovascular risk assessment, an electrocardiograph and an echocardiogram. Blood pressure was measured while seated on two occasions at least 20 minutes apart. Any abnormalities or new conditions that were detected triggered referral to either a local general practitioner or local hospital for specialist care, as clinically indicated and appropriate. Ethics approval was gained from the Multi-Region Ethics Committee (MEC/06/03/026).

\section{Echocardiography methods}

A standard protocol was developed that included two dimensional, m-mode and Doppler images obtained in the parasternal long and short axis, the apical four, five and two chamber views, and subcostally when required. A brief screening scan that included anatomical and functional parameters as described below was undertaken (including subjective assessment of all chamber size and valve function). Suspected abnormalities were not interrogated fully at the research clinic, but instead referred for full echocardiography at a later date. There were two exceptions where we referred the participants immediately to the local cardiology service: one participant with a previously undiagnosed left atrial myxoma and another with significant regional wall motion abnormalities who was experiencing angina during the echo examination.

Most of the echocardiograms were performed using one of two machines: Sonosite MicroMaxx or Sonosite MTurbo with a broadband 1-5 $\mathrm{MHz}$ phased array transducer. On two occasions, for logistical reasons, we used an Acuson Cypress and a Philips CX50. A team of experienced sonographers (see acknowledgements) performed the echocardiography and initial measurements. The images were immediately reviewed, and over-measured when needed by a single observer (GW). All images were digitally stored and retained for future review if required. Each screening echo was performed in about 10 minutes.

The following measurements were obtained: 1) m-mode measurements: left ventricular end-diastolic dimension (LVEDD), left ventricular end-systolic dimension (LVESD), interventricular septal thickness (IVS), posterior left ventricular wall thickness (PW), left atrial diameter (LAD), and aortic root diameter (AoD); 2) two-dimensional measurements: left atrial area (LAA) obtained from the apical four chamber view; 3 ) Doppler mitral early to late filling velocity ratio $(E: A)$, and peak aortic velocity; mitral early to late filling velocity ratio (E:A); and 4) tissue Doppler medial mitral annular early diastolic descent velocity (Ea). From these measurements, the following were calculated: left ventricular (LV) mass using the ASE recommended $\mathrm{m}$-mode method; ${ }^{12}$ fractional shortening (FS) and ejection fraction (LVEF). The ratio or E:Ea was also calculated and mitral filling pattern derived from the combination of these measurements. We used ASE gender-based references values to determine the presence (or absence) of LVH based on LV mass index. ${ }^{12}$

\section{Statistical analysis}

Analyses were carried out in SAS 9.1. Analysis of variance (ANOVA) was used to compare the differences between the three cohorts (rural Māori, urban Māori and urban non-Māori) on quantitative variables. Logistic regression was used to determine the contributors to $\mathrm{LVH}$, and the following variables were included: urban Māori, rural Maori, age, gender and estimated Framingham CVD risk, which incorporates other conventional risk factors (e.g. T2DM, hypertension, smoking). Both Māori cohorts were compared to the urban non-Māori cohort.

\section{Results}

We have previously reported the CVD risk profiles of these cohorts ${ }^{8}$ that include 252 rural Māori participants, 243 urban Māori participants and 256 urban non-Māori 
participants and demonstrated elevated blood pressure, hyperlipidaemia, higher rates of obesity and smoking particularly in rural Maori. Briefly, the mean age in the rural Māori was higher (45.7 years) than both of the other groups (42.6 for the urban Mãori cohort and 43.6 for the non-Māori group) (Table 1). Gradual increases in systolic blood pressure were observed, with the highest values in the rural Māori cohort and the lowest in the non-Māori cohort, although this was less pronounced for diastolic blood pressure. Height, weight and measures of obesity (BMI, BSA) indicate that obesity may be more prevalent in the rural Mãori cohort than the urban Māori or non-Māori cohorts, but fatfree mass was not different across the groups. Measures of T2DM (fasting blood glucose, $\mathrm{HbA} 1_{\mathrm{C}}$ and insulin) were highest in the rural Māori, followed by urban Māori and lowest in the non-Māori cohort. Similarly, the rates of previously diagnosed and newly detected elevated blood markers of diabetes were highest in the rural Māori, followed by urban Māori and lowest in the non-Māori cohort.

\section{Echocardiographic measurements}

The structural measurements of the heart suggest that the rural Māori cohort had the largest hearts and the urban non-Māori cohort the smallest hearts (Table 2). The left ventricular diastolic dimension was highest in the rural Māori cohort, smallest in the nonMāori cohort, and intermediate in the urban Māori cohort. No differences were detected in the systolic dimensions. Other measures of heart size (left atrial diameter, aortic root diameter and left atrial area) showed similar trends. This was also apparent for left ventricular wall thickness and calculated mean LVM (183.5 [SD 61.4] versus 169.7 [SD 57.1] versus 152.6 [SD 46.7] $p<0.001$ ). In order to account for body size, LVM was indexed to either BSA, height or fat-free mass. The differences persisted: LVM was consistently highest in the rural Māori cohort and consistently lowest in the non-Māori cohort. Using the ASE recommended cut points of $\mathrm{LVH}, 238$ of the 737 participants (32.3\%) in whom LVM was available met the genderbased criteria for LVH. The prevalence of LVH was higher in both Māori cohorts and highest in the rural Māori cohort. The prevalence also increased with age and, with the exception of the youngest age band, this was true for all of the groups (Figure 1). Across all but the youngest age band, more participants in the two Māori cohorts met the ASE LVH criteria

\begin{tabular}{|c|c|c|c|c|}
\hline & $\begin{array}{c}\text { Rural Māori } \\
\text { Mean (sd) } \\
N=252\end{array}$ & $\begin{array}{l}\text { Urban Māori } \\
\text { Mean (sd) } \\
\text { N=243 }\end{array}$ & $\begin{array}{l}\text { Urban Non-Mãori } \\
\qquad \begin{array}{c}\text { Mean (sd) } \\
N=256\end{array}\end{array}$ & $\begin{array}{l}\text { ANOVA or } \\
{ }^{*} \text { Chi-Square }\end{array}$ \\
\hline Age, years & $45.7(11.5)$ & $42.6(11.2)$ & $43.6(11.5)$ & 0.00908 \\
\hline Gender, male & $102(40.5 \%)$ & $110(45.3 \%)$ & $125(91.9 \%)$ & 0.166 \\
\hline Systolic BP, mmHg & $130.1(20.1)$ & $128.3(20.6)$ & $124.5(14.8)$ & 0.00264 \\
\hline Diastolic BP, mmHg & $85.3(11.1)$ & $86.2(13.6)$ & $83.1(12.1)$ & 0.01821 \\
\hline Height, $\mathrm{m}$ & $168.4(8.6)$ & $169.2(9.1)$ & $170.6(9.3)$ & 0.02868 \\
\hline Weight, $\mathrm{kg}$ & $87.2(21.9)$ & $83.6(20.0)$ & $76.0(15.0)$ & $<0.001$ \\
\hline Body Mass Index, kg/m² & $30.7(7.3)$ & $29.1(6.4)$ & $26.1(4.5)$ & $<0.001$ \\
\hline Fat Free Mass, kg & $55.2(11.2)$ & $55.8(12.3)$ & $53.8(10.55)$ & 0.11414 \\
\hline Body surface area, $\mathrm{m}^{2}$ & $1.96(0.24)$ & $1.93(0.23)$ & $1.87(0.21)$ & $<0.001$ \\
\hline Fasting blood glucose, $\mathrm{mmol} / \mathrm{L}$ & $5.8(1.66)$ & $5.4(0.91)$ & $5.3(0.54)$ & $<0.001$ \\
\hline HBA1C & $6.3(1.43)$ & $5.4(0.85)$ & $5.2(0.56)$ & $<0.001$ \\
\hline Plasma insulin, pmol/L & $71.6(64.8)$ & $52.4(54.3)$ & $42.4(34.27)$ & $<0.001$ \\
\hline Creatinine, umol/L & $79.7(50.7)$ & $81.7(18.4)$ & $81.8(12.5)$ & 0.71684 \\
\hline eGFR, $\mathrm{ml} / \mathrm{min} / 1.73 \mathrm{~m}^{2}$ & $85.6(22.5)$ & $84.1(13.0)$ & $83.9(13.3)$ & 0.459 \\
\hline \multicolumn{5}{|l|}{ Co-morbidities: } \\
\hline Prior hypertension, $\mathrm{n}(\%)$ & $40(16 \%)$ & $36(15 \%)$ & $26(10 \%)$ & $<0.001$ \\
\hline Newly identified hypertension, (\%) & $56(22 \%)$ & $57(24 \%)$ & $45(18 \%)$ & 0.235 \\
\hline Prior dyslipidaemia, n (\%) & $40(16 \%)$ & $17(7.1 \%)$ & $7(3 \%)$ & 0.1407 \\
\hline Newly identified dyslipidaemia, $\mathrm{n}(\%)$ & $107(43 \%)$ & $134(55 \%)$ & $108(42 \%)$ & 0.008 \\
\hline Type 2 diabetes, n (\%) & $29(3.9 \%)$ & $11(1.5 \%)$ & $7(0.93 \%)$ & $<0.001$ \\
\hline $\begin{array}{l}\text { New detection of fasting blood glucose or } \\
\text { HBA1c } n(\%)\end{array}$ & $64(29.4 \%)$ & $22(9.5 \%)$ & $16(6.5 \%)$ & $<0.001$ \\
\hline
\end{tabular}

\section{Table 2: Baseline echocardiographic measurements.}

\begin{tabular}{|c|c|c|c|c|c|c|c|}
\hline & \multicolumn{2}{|c|}{ Rural Māori } & \multicolumn{2}{|c|}{ Urban Mãori } & \multicolumn{2}{|c|}{ Urban Non-Mãori } & \multirow[t]{2}{*}{ ANOVA } \\
\hline & $\mathrm{N}$ & Mean (sd) & $\mathrm{N}$ & Mean (sd) & $\mathrm{N}$ & Mean (sd) & \\
\hline \multicolumn{8}{|l|}{ Measurements of heart size } \\
\hline Left ventricular end-diastolic dimension, $\mathrm{mm}$ & 250 & $52.8(6.0)$ & 238 & $52.4(5.7)$ & 255 & $51.4(5.22)$ & 0.03 \\
\hline Left ventricular end-systolic dimension, $\mathrm{mm}$ & 243 & $32.1(5.0)$ & 238 & $31.63(5.7)$ & 252 & $31.2(4.9)$ & 0.11 \\
\hline Interventricular septal thickness, mm & 247 & $9.3(1.78)$ & 239 & $8.96(1.94)$ & 255 & $8.49(1.81)$ & $<0.001$ \\
\hline Posterior wall thickness, mm & 247 & $9.2(1.87)$ & 238 & $8.61(1.87)$ & 255 & $8.14(1.72)$ & $<0.001$ \\
\hline Left atrial dimension, $\mathrm{mm}$ & 239 & $37.8(6.1)$ & 235 & $37.3(5.4)$ & 253 & $36.4(5.5)$ & 0.02 \\
\hline Left atrial dimension index, $\mathrm{mm} / \mathrm{m}^{2}$ & 239 & $19.4(2.9)$ & 235 & $19.4(2.5)$ & 253 & $19.5(2.8)$ & 0.78 \\
\hline Aortic root dimension, $\mathrm{mm}$ & 218 & $34.0(4.8)$ & 235 & $32.6(4.8)$ & 253 & $30.9(4.9)$ & $<0.001$ \\
\hline Aortic root dimension, $\mathrm{mm} / \mathrm{m}^{2}$ & 218 & $17.4(2.5)$ & 235 & $14.7(2.3)$ & 253 & $16.5(2.3)$ & $<0.001$ \\
\hline Left atrial area, cm2 & 239 & $21.6(5.2)$ & 234 & $21.4(4.8)$ & 248 & $20.7(4.2)$ & 0.08 \\
\hline \multicolumn{8}{|l|}{ Systolic function measurements } \\
\hline Left ventricular fractional shortening, $\%$ & 235 & $39.1(6.0)$ & 230 & $39.8(6.4)$ & 247 & $39.9(6.5)$ & 0.33 \\
\hline Left ventricular ejection fraction, $\%$ & 168 & $67.7(8.6)$ & 224 & $68.8(9.3)$ & 243 & $69.6(8.0)$ & 0.10 \\
\hline \multicolumn{8}{|l|}{ Diastolic function measurements } \\
\hline Mitral valve E velocity, $\mathrm{cm} / \mathrm{s}$ & 250 & $67.0(17.2)$ & 240 & $71.6(16.0)$ & 256 & $76.3(17.1)$ & $<0.001$ \\
\hline Mitral valve A velocity, $\mathrm{cm} / \mathrm{s}$ & 246 & $61.0(17.1)$ & 238 & $56.8(17.4)$ & 255 & $56.0(15.2)$ & 0.002 \\
\hline$E: A$ & 246 & $1.17(0.42)$ & 238 & $1.36(0.49)$ & 255 & $1.5(0.83)$ & $<0.001$ \\
\hline Mitral annular E velocity, $\mathrm{cm} / \mathrm{s}$ & 248 & $8.51(2.62)$ & 238 & $10(2.80)$ & 251 & $10.5(2.66)$ & $<0.001$ \\
\hline Mitral E:Annular E velocity, & 243 & $8.24(2.39)$ & 235 & $7.57(2.64)$ & 251 & $7.54(2.23)$ & 0.002 \\
\hline \multicolumn{8}{|l|}{ Calculation of left ventricular mass } \\
\hline Left ventricular mass, $g$ & 247 & $183.5(61.4)$ & 236 & $169.7(57.1)$ & 255 & $152.6(46.7)$ & $<0.001$ \\
\hline Left ventricular mass/body surface area, $\mathrm{g} / \mathrm{m}^{2}$ & 246 & $92.7(24.8)$ & 236 & $87.1(23.8)$ & 255 & $80.8(20.4)$ & $<0.001$ \\
\hline Left ventricular mass/height, $\mathrm{g} / \mathrm{m}$ & 246 & $108.6(34.6)$ & 236 & $99.8(31.4)$ & 255 & $89.0(25.2)$ & $<0.001$ \\
\hline Left ventricular mass/fat free mass, $\mathrm{g} / \mathrm{kg}$ & 240 & $3.31(0.81)$ & 232 & $3.05(0.76)$ & 254 & $2.84(0.66)$ & $<0.001$ \\
\hline
\end{tabular}


and, further to this, LVH detection was highest in the rural Māori cohorts in all age bands. Similarly, LVH prevalence fell intermediate to the others in the urban Mãori cohort (Table 3). In logistic regression with multiple predictors, the only independent predictors of LVH were being in the rural Māori cohort $(p=0.0001)$, age $(p<0.0001)$ and gender ( $p=0.0048$ ). Being in the urban Māori cohort did not reach significance $(p=0.075)$, nor did the 5-year CVD risk score (0.084) (Table 4). This analysis was repeated with $\mathrm{BMI}$ in the model and, although BMI was an important and significant contributor to the model, the contributions and significance of the other variables was not affected.

With regard to cardiac function, measures of systolic function were similar across all three groups, although diastolic parameters consistently showing that rural Māori have the worst diastolic filling profile: E:A 1.17 (SD 0.42 ) versus 1.36 (SD 0.49) for urban Māori and 1.50 (0.83) for urban non-Māori, $p<0.001$; and the highest E:Ea (8.2 (SD 2.4) versus 7.6 (SD 2.6) for urban Māori and 7.54 (2.23) for urban non-Māori, $p=0.002$. (Table 2). Regional wall motion abnormalities were observed in 51 participants, of which 31 included more than one wall segment. These were less frequently seen in the urban non-Māori cohort (2/31) than the urban Māori cohort (6/31) and the rural Māori cohort (13/31); however, single wall motion abnormalities were more frequently observed in the urban non-Māori and rural Māori cohorts (12/31 in both) compared to the urban Māori cohort (6/31). A history of rheumatic fever was reported most frequently in the rural Māori cohort (24/252) and the urban Māori cohort $(10 / 243)$ and least in the urban non-Māori cohort (2/256). Overall, there were only three cases of significant valve disease: one with a prosthetic valve and two with mild-moderate mitral valve disease. No significant valve disease was detected.

\section{Discussion}

This study has highlighted the higher prevalence of structural heart abnormalities in Māori participants, especially those who live in a rural setting. This is the first study of its kind to perform population-based screening with echocardiography in NZ, and it has revealed some interesting findings that could have important implications for the management and prevention of CVD, especially in NZ Māori, and potentially in any remote high-risk population.

For many years, it has been known that the rate of CVD is higher in Māori and that CVD presents earlier in Māori. ${ }^{2}$ The larger study, of which this is a sub-analysis, was designed to investigate the spectrum of possible reasons why this may occur. In the first publication from this population-based study, we have reported that obesity, smoking, hypertension, dyslipidaemia, T2DM, and calculated CVD risk are higher in rural versus urban Māori and higher than the non-Maori cohort. ${ }^{8}$

This paper adds to that work by demonstrating a higher prevalence of structural heart abnormalities in the rural and urban Māori cohorts than in the nonMaori cohort. A key finding of this study was the significantly higher left ventricular wall thickness, resulting in higher LVM across the groups (rural Māori having the highest values and non-Māori the lowest) and reflected in the prevalence of LVH data as well. Overall, the prevalence of LVH in the study was about one-third; however, this is not evenly distributed among the three cohorts. Rural Māori have the highest rates of LVH: $75 \%$ in those aged $60-69$ years; $54 \%$ in those aged $40-49$ years; and about $40 \%$ in those aged 40-49 years. But, between 40 and 60 years, both Māori cohorts had much higher incidence of LVH than the non-Maori cohort. These differences persisted after indexation of LVM to any measure of body size.

The reasons for the high prevalence of $\mathrm{LVH}$ in these communities are likely to be multifaceted. We have already demonstrated higher calculated CVD risk in these cohorts and suboptimal treatment according to CVD guidelines. ${ }^{8}$ Undoubtedly, co-morbidity such as hypertension and T2DM play a role, since both are precursors for the development of LVH. The rural and urban Māori cohorts in this study had a prevalence of T2DM of around $11 \%$ and diagnosed hypertension of about $25 \%,{ }^{8}$ but we did identify further cases of undiagnosed hypertension in the rural Māori cohort (22\%), the urban Māori cohort (24\%) and the urban non-Māori cohort (18\%). ${ }^{8}$ Lastly, even when body size was taken into account, LVH was linked to obesity (as measured by BMI) in these cohorts. The high rates of LVH may reflect this disease burden, but it may also represent poor management of disease.

Worldwide, there are differences in the prevalence of many health-related conditions,

\section{Figure 1: ASE defined LVH by age and cohort.}

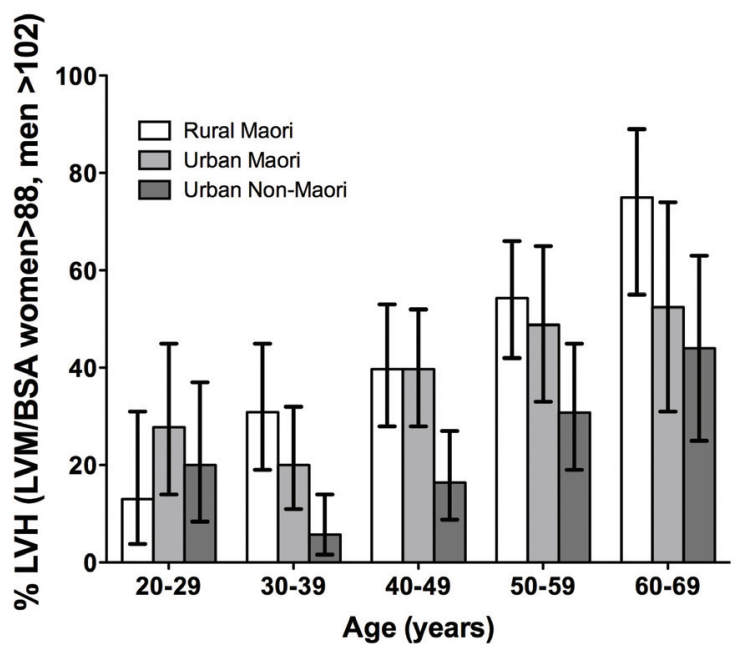

\begin{tabular}{|c|c|c|c|}
\hline Age Band years & $\begin{array}{c}\text { Rural Mãori } \\
\text { \%LVH } \\
\text { (95\% Cl lower, upper) }\end{array}$ & $\begin{array}{l}\text { Urban Mãori } \\
\text { \%LVH } \\
\text { (95\% Cl lower, upper) }\end{array}$ & $\begin{array}{c}\text { Urban non-Māori } \\
\text { \%LVH } \\
\text { (95\% Cl lower, upper) }\end{array}$ \\
\hline $20-29$ & $13.0(2.80-31.0)$ & $27.8(14.0-45.0)$ & $20.0(8.4-37.0)$ \\
\hline $30-39$ & $30.9(19.0-45.0)$ & $20.0(11.0-32.0)$ & $5.7(1.6-14.0)$ \\
\hline $40-49$ & $39.7(28.0-53.0)$ & $39.7(28.0-52.0)$ & $16.4(8.8-27.0)$ \\
\hline 50-59 & $54.3(42.0-66.0)$ & $48.8(33.0-65.0)$ & $30.8(19.0-45.0)$ \\
\hline $60-69$ & $75.0(55.0-89.0)$ & $52.4(31.0-74.0)$ & $44.0(25.0-63.0)$ \\
\hline Overall, N (\%) & 105 (42.7\%) & $83(35.2 \%)$ & $50(19.6 \%)$ \\
\hline
\end{tabular}

Table 4: Multivariable logistic regression predictors of LVH (LVM/BSA cut point by gender).

\begin{tabular}{llll} 
Model parameter & Odds Ratio & $95 \% \mathrm{Cl}$ & P value \\
\hline Urban Māori $^{\text {a }}$ & 1.91 & $1.29,2.84$ & 0.74 \\
\hline Rural Māori $^{\text {a }}$ & 3.26 & $2.22,4.80$ & $<0.001$ \\
\hline Age, per year & 1.03 & 1.02 .1 .05 & $<0.001$ \\
\hline Gender, male & 0.76 & $0.55,1.04$ & $<0.08$ \\
\hline 5 year CVD Risk $>$ 15\% & 1.78 & $1.08,2.9$ & 0.02 \\
\hline a: Relative to reference group of urban non-Maori & & \\
\hline
\end{tabular}


although not consistently in one direction. The reasons for disparity when they exist are complex, but include individual and community action, health system and government policies. ${ }^{13}$ This is confounded in countries such as Australia and NZ, where the indigenous people comprise a higher proportion of rural inhabitants and the impacts of colonisation are reflected in economic disadvantage. ${ }^{14}$

Recently, using geographical information systems, it has been shown that the distance is a barrier to both having blood pressure measured and to visiting a GP or filling a prescription. ${ }^{15}$ This is particularly relevant in rural NZ, which is typically quite sparsely populated. In addition, these areas are also often the most economically deprived. There are significant challenges facing the future of general practice and access to rural general practice is a priority for NZ. ${ }^{16}$ Any improvements in this service provision should alleviate some of the differences observed in this study. However, there is also a disparity among NZ's regional hospitals in terms of cardiovascular services. For example, patients who present at smaller regional centres are less likely to receive effective treatment for acute coronary syndromes in a timely manner, ${ }^{17}$ and we know that there are geographical differences in the provision of echocardiography throughout NZ with some of the most remote areas performing the least number of echocardiograms. ${ }^{18}$ Yet echocardiography is an excellent way to assess LVH and to quantify LVM. Left ventricular hypertrophy is a modifiable CVD risk factor - most modern antihypertensive treatments have been shown to decrease $\mathrm{LVM}^{19}$ - and so the detection of $\mathrm{LVH}$ should be a priority in high-risk patient groups.

The definition of LVH by echocardiography requires reliable normal reference ranges. One of the challenges is how to define normal limits for individuals of different size and the ASE recommend indexation to account for body size. ${ }^{12}$ Historically, this has meant dividing the LVM by body surface area, the so-called LVM index (LVMI). The challenge with using BSA as the indexation variable is that it forgives LVH in obese individuals and, conversely, over-estimates LVH in thin individuals. ${ }^{20}$ More recently, it has been suggested that height be used as the indexation variable of choice, ${ }_{1}^{21}$ which alleviates the under detection in obesity, but as height does not change over time the impact of increased weight is not taken into account. It has been demonstrated that the most significant determinant of LVM is fat-free mass ${ }^{22,23}$ since it takes into account metabolically active soft tissue, and not the rather inert fat mass. Unfortunately, reference ranges for LVM indexed to fat-free mass do not exist.

It is entirely feasible that using the ASE LVM thresholds in this study has resulted in an 'over definition' of $\mathrm{LVH}$ and that if fat-free mass reference ranges were available then $\mathrm{LVH}$ prevalence would drop significantly because fat-free mass is ethnic-dependent. ${ }^{24,25}$ Māori have higher fat-free mass for a given weight compared to European cohorts. ${ }^{25}$ However, if the differences observed in this study were related to over-diagnosing LVH on this basis, then the LVM indexed to fat-free mass would be the same in all three groups, but it is not. Similarly, the indexed LVM would be the same for both Māori groups if this was related to ethnicity and body composition alone. The gradual increase observed in unindexed LVM - highest in rural Māori, lowest in urban non-Māori, intermediate in urban Māori persisted despite any indexation method, suggesting that a real difference in LVH may be present. The addition of a rural non-Māori cohort, which we did not have, may have added extra clarification in this regard.

Further support for a pathological difference in LVH may be garnered from the other echocardiographic data showing a worse diastolic profile that is aligned with increased prevalence of $\mathrm{LVH}$, and this is more evident in the Māori and rural Māori participants in particular. In a recent systematic review, we have shown geographic (and thus ethnic) differences in LVM, ${ }^{26}$ indicating that there is a need for ethnic-specific reference ranges of echocardiography. But, even if there were Māori reference ranges available, it is unlikely that the use of these would eliminate the LVH altogether. It is interesting to note that in the multivariable predictors of $\mathrm{LVH}$, age and gender were important predictors, as was being in the rural Māori group. Neither CVD risk, nor being in the urban Māori group, quite reached significance in the model. This suggests the LVH observed in this study is not simply related to ethnicity, nor is it just a marker of worse CVD risk, and it may offer additional information beyond the usual screening parameters.

Does this study support population-based echocardiographic screening in the Mãori community? For a screening program to be effective there needs to be a readily available test and readily available treatment. In this case, the test is echocardiography, which has the potential to be applied widely. Other tests, such as electrocardiography (ECG), are poor markers of $\mathrm{LVH}$. In a cohort of patients with T2DM, we recently demonstrated the superiority of echocardiography over ECG $-60 \%$ of patients with T2DM had echo-defined LVH versus virtually none with $\mathrm{ECG}^{27}$ - providing a good rationale for echocardiographic screening patients with T2DM with echocardiography, partly in order detect any other evidence of CAD. Therefore, it would be reasonable to suggest that all adult Māori undergo an echocardiogram, especially given we have already reported that CVD risk (including hypertension) is elevated and often unnoticed and undertreated. ${ }^{8}$ However, when to start such a screening program and how often to repeat the test cannot be addressed from the current data, and such a screening program would be expensive to implement.

In terms of treatment, regression of LVH is achieved through management of hypertension - most of the modern antihypertensive agents have been shown to regress LVH in clinical trials. ${ }^{19}$ As previously discussed, the degree of hypertension was underestimated in the three cohorts prior to the study, so improved hypertension identification, monitoring and treatment should be the first step, and the role of 24-hour ambulatory blood pressure could be explored in this cohort. The addition of echocardiography to detect LVH may or may not be useful if the management of hypertension is improved. Furthermore, if obesity were able to be reduced, it is conceivable that there may be a favourable impact on LVH as well.

The increasing availability of hand-carried ultrasound could make screening for LVH more widely accessible. But there are barriers to overcome, such as who would provide this service and how many hand-carried devices would be required. For example, the NZ healthcare system is largely a public-funded system where echocardiography is performed in association with a hospital. There is already significant variation (3-4 fold difference) in the delivery and number of scans performed per population served through each hospital. ${ }^{18}$ The system is already stretched in terms of equipment and manpower, and this is especially true in rural areas. Any additional screening would have to fall outside of the current service. Despite the challenges that 
implementing a screening program would create, the imbalance and burden of disease identified through this research has been apparent and troubling for some time. Although there is no technical reason why hand-carried ultrasound may underperform in this setting, there are challenges with imaging patients with larger chests. We have compared cardiology-fellow performed echocardiography with expert sonographer measurements obtained with a full cart system and found that, for detection of LVH, the sensitivity was $75 \%$, specificity $94 \%$, positive predictive value $79 \%$ and negative predictive value was 93\% (unpublished data) in a separate cohort of patients with type 2 diabetes. ${ }^{27}$ In the current study, expert sonographers collected and measured all of the images, so image quality is unlikely to have affected our results.

\section{Conclusion}

In this study, structural and functional changes in the heart were present at higher rates in Māori and especially rural Māori, compared to an urban non-Māori population. This data supports the importance of our previous report of high CVD risk and under diagnosis and under treatment in Māori and especially rural Māori, and is consistent with other studies that consistently demonstrate disparities in CVD disease prevalence, age of CVD onset, confluence of risk factors (including smoking, T2DM and hypertension) and access to health care services.

\section{Acknowledgements}

This work was supported by project grants from the Health Research Council of NZ and the National Heart Foundation. Additional support was provided by PHARMAC, Hawkes Bay District Health Board and Canterbury District Health Board. Support in kind (loan of ultrasound equipment) was provided by Fujifilm Sonosite. We thank the Wairoa community (the participants and their whanau, Wairoa Taiwhenua, the general practice surgeries and Māori health providers); the Christchurch Community (the participants and their whanau, Mana whenua ki Waitaha, Pegasus Health and Christchurch primary health care organisations); and the Māori Advisory Group for the Hauora Manawa project. We are grateful to Professor Gary Nicholls, Dr John Irvine, Dr Cameron Lacey and Wendy Dallas-Katoa for clinical assistance.
We are particularly appreciative of the team of sonographers who assisted with this study: Helen Walsh, Gina Wadams, Andrew Yeadon and Renelle French.

\section{References}

1. Robson B, Purdie G. Mortality. In: Robson B, Harris R, eds. Hauora:MāoriStandards of HealthIV. A Study of the Years 2000-2005. Wellington (NZ): University of Otago Department of Public Health The Eru Pōmare Māori Health Research Centre; 2007. p. 33-61.

2. Curtis $E_{1}$ Harwood M, Riddell T. Cardiovascular disease. In: Robson B, Harris R, eds. Hauora: Māori Standards of Health IV. A Study of the Years 2000-2005. Wellington (NZ): University of Otago Department of Public Health The Eru Pōmare Mãori Health Research Centre; 2007.p. 141-60.

3. Feigin V, Carter K, Hackett M, Barber PA, McNaughton $\mathrm{H}$, Dyall $\mathrm{L}$, et al. Ethnic disparities in incidence of stroke subtypes: Auckland regional community stroke study, 2002-2003. Lancet Neurol. 2006;5:130-9.

4. Mihaere KM, Harris R, Gander PH, Reid PM, Purdie G, Robson B, et al. Obstructive sleep apnea in New Zealand adults: Prevalence and risk factors among Maori and non-Maori. Sleep. 2009;32:949-56.

5. Lim S, Chellumuthi C, Crook N, Rush E, Simmons D. Low prevalence of retinopathy, but high prevalence of nephropathy among Maori with newly diagnosed diabetes-te wai o rona: Diabetes prevention strategy. Diabetes Res Clin Pract. 2008:80:271-4.

6. Gentles D, Metcalf P, Dyall L, Scragg R, BlackP, Schaaf D, Sundborn G, Jackson R. Blood pressure prevalences and levels for a multicultural population in Auckland, New Zealand: Results from the diabetes, heart and health survey 2002/2003. N Z Med J. 2006;119(1245):U2318. PubMed PMID: 17146492.

7. Sundborn G, Metcalf P, Scragg R, Schaaf D, Dyall L Gentles $D$, et al. Ethnic differences in the prevalence of new and known diabetes mellitus, impaired glucose tolerance, and impaired fasting glucose. Diabetes heart and health survey (dhah) 2002-2003, Auckland New Zealand. N Z Med J. 2007;120(1257):U2607. PubMed PMID: 17632597.

8. Cameron VA, Faatoese AF, Gillies MW, Robertson PJ, Huria TM, Doughty RN, et al. A cohort study comparing cardiovascular risk factors in rural maori, urban maori and non-maori communities in New Zealand. BMJ Open. 2012;2:e000799 doi:10.1136/ bmjopen-2011-000799.

9. New Zealand Guidelines Group. New Zealand Cardiovascular Guidelines Handbook: A Summary Resourcefor Primary CarePractitioners. Wellington (NZ) New Zealand Ministry of Health; 2009.

10. Pitama S, Wells JE, Faatoese A, Tikao-Mason K, Robertson $\mathrm{P}$, Huria T, et al. A kaupapa maori approach to a community cohort study of heart disease in New Zealand. Aust NZ J Public Health. 201 1;35:249-55.

11. Smith L. Decolonizing Methodologies. Dunedin (NZ): University of Otago Press; 1999.

12. Lang RM, Bierig M, Devereux RB, FlachskampfFA, Foster E, Pellikka PA, et al. Recommendations for chamber quantification: A report from the American Society of Echocardiography's guidelines and standards committee and the chamber quantification writing group, developed in conjunction with the European Association of Echocardiography, a branch of the European Society of Cardiology.J Am Soc Echocardiogr. 2005;18:1440-63.
13. Smith KB, Humphreys JS, Wilson MG. Addressing the health disadvantage of rural populations: How does epidemiological evidence inform rural health policies and research? Aust J Rural Health. 2008;16:56-66.

14. Ministry of Health. Mätätuhi Tuawhenua: Health of RuralMāori2012. Wellington (NZ): Government of New Zealad; 2012

15. Hiscock R, Pearce J, BlakelyT, Witten K. Is neighborhood access to health care provision associated with individual-level utilization and satisfaction? Health Serv Res. 2008;43:2183-200.

16. Goodyear-Smith F, Janes R. New Zealand rural primary health care workforce in 2005: More than just a doctor shortage. Aust J Rural Health. 2008;16:40-6.

17. Ellis C, Devlin G, Elliott J, Matsis P, Williams M, Gamble $\mathrm{G}$, et al. Acute Coronary Syndrome patients in New Zealand experience significant delays to access cardiac investigations and revascularisation treatment especially when admitted to non-interventional centres: Results of the second comprehensive national audit of Acute Coronary Syndrome patients. NZMed J. 2010;123:44-60.

18. Bridgman PG, Ashrafi AN, Mann S, Whalley GA, Collaborators S. Survey of clinical echocardiography in New Zealand (SCANZ). NZMed J. 2008;121:34-44.

19. Schmieder RE, Schlaich MP, Klingbeil AU, Martus P. Update on reversal of left ventricular hypertrophy in essential hypertension (a meta-analysis of all randomized double-blind studies until December 1996). Nephrol Dial Transplant. 1998;13:564-9.

20. Lauer MS, Anderson KM, KannelWB, Levy D. The impact of obesity on left ventricular mass and geometry. The Framingham Heart Study. JAMA. 1991;266:231-6.

21. de Simone G, Daniels SR, Devereux RB, Meyer RA, Roman MJ, de Divitiis O, et al. Left ventricular mass and body size in normotensive children and adults: Assessment of allometric relations and impact of overweight. J Am Coll Cardiol. 1992;20:1251-60.

22. Hense HW, Gneiting B, Muscholl M, Broeckel U, Kuch $B$, Doering A, et al. The associations of body size and body composition with left ventricular mass: Impacts for indexation in adults. J Am Coll Cardiol. 1998:32:451-7.

23. Whalley GA, Gamble GD, Doughty RN, Culpan A, Plank $L$, MacMahon S, et al. Left ventricular mass correlates with fat-free mass but not fat mass in adults.J Hypertens. 1999;17:569-74.

24. Ward LC, Heitmann BL, Craig P, Stroud D, Azinge EC, Jebb S, et al. Association between ethnicity, body mass index, and bioelectrical impedance. Implications for the population specificity of prediction equations. AnnNY Acad Sci. 2000;904:199-202.

25. RushEC, Freitas I, PlankLD. Body size, body composition and fat distribution: Comparative analysis of European Maori, Pacific Island and Asian Indian adults. Br J Nutr. 2009;102:632-41.

26. Poppe KK, Bachmann ME, Triggs CM, Doughty RN, Whalley GA. Geographic variation in left ventricular mass and mass index: A systematic review. J Hum Hypertens. 2012;26:420-9.

27. Somaratne JB, Whalley GA, Poppe KK, ter Bals MM Wadams G, Pearl A, et al. Screening for left ventricular hypertrophy in patients with type 2 diabetes mellitus in the community. Cardiovasc Diabetol. 2011;10:29 